\section{Effects of Light, Scarification, and Gibberellic Acid on Seed Germination of Eight Pedicularis Species from Yunnan, China}

\author{
Ai-Rong Li \\ Kunming Institute of Botany, Chinese Academy of Sciences, 134 Lan-Hei \\ Road, Kunming, Yunnan, China, 650204; and Graduate School of the \\ Chinese Academy of Sciences, Beijing, China, 100039
}

\section{Kai-Yun Guan ${ }^{1}$ \\ Kunming Institute of Botany, Chinese Academy of Sciences, 134 Lan-Hei Road, Kunming, Yunnan, China, 650204}

\author{
Robin J. Probert \\ The Royal Botanic Gardens, Kew, Wakehurst Place, Ardingly, West Sussex \\ RH17 6TN, UK
}

Additional index words. alpine plant, ecological adaptation, hemiparasitism, Orobanchaceae, seed bank

\begin{abstract}
Seeds of most Pedicularis species do not germinate easily and uniformly, which hinders the process of seeking solutions for successful cultivation of these taxa. In an attempt to determine optimal conditions and effective methods for uniform, rapid, and high-percent germination, the effects of light, scarification, and gibberellic acid $\left(\mathbf{G A}_{3}\right)$ were tested on seed germination of eight Pedicularis species from nine sites in the northwestern Yunnan Province of China. There were some differences in germination characteristics among the tested species. Seed germination of some species was promoted by light, but not in others. Wet-habitat species generally had positive photoblastic responses. For many species, scarification was effective to promote seed germination, but neither 100 nor $500 \mathrm{mg} \cdot \mathrm{L}^{-1} \mathrm{GA}_{3}$ had consistent promoting effects.
\end{abstract}

Pedicularis L. belongs to the family Orobanchaceae (Angiosperm Phylogeny Group, 2003) and most of its members are root hemiparasites that partially depend on host plants for nutrients (Tsoong, 1963). The genus is mainly distributed in frigid, highlatitude, and alpine belts in the north temperate zone (Yang et al., 1998). As one of the largest genera of angiosperms in the northern hemisphere $(\approx 600$ species worldwide) and with dramatic morphological diversity (Ree, 2005), Pedicularis species have long been valuable materials for biological research, particularly pollination biology (Macior, 1975, 1983; Macior and Tang, 1997; Wang et al., 2003). Along with striking shapes and colors, they have a long flowering period (2-3 months on average), giving them a great

Received for publication 4 Jan. 2007. Accepted for publication 7 Mar. 2007.

This research is supported by the National Natural Science Foundation of China (no. 30670207).

We are grateful to Prof. Carol Baskin and Prof. Jerry Baskin of the University of Kentucky for their generous help and critical reading of an earlier version of the manuscript. We thank the anonymous reviewers for their instructive comments and valuable suggestions that improved this manuscript.

${ }^{1}$ To whom reprint requests should be addressed; e-mailguanky@mail.kib.ac.cn potential for being developed into popular ornamental plants. Furthermore, chemical constitutes of many Pedicularis species are shown to have special pharmacological effects (Wang and Jia, 1995; Wu et al., 2002; Zhu, 1997).

Unfortunately, although widespread in natural habitats, no successful cultivation of Pedicularis has ever been achieved. Although they are abundant in the wild, studies of these plants are limited and their utilization is greatly hindered because their habitats are not easily accessible and it is difficult to collect materials. What makes things worse is that some species have been listed as threatened or endangered and are in dire need of immediate protection (Allard, 2001; Canadian Endangered Species Conservation Council, 2002; Marvier and Smith, 1997). Thus, conservation of biodiversity also calls for successful introduction and cultivation of Pedicularis L.

In the process of seeking solutions for cultivation, large numbers of seedlings are needed. However, seeds of this genus often germinate slowly, nonuniformly, and in low percentages (Jensen, 2004; Kaye, 1997; McDonough, 1970). Therefore, effective methods must be found to obtain uniform and rapid germination with a high percentage of germination.
In this study, our aim was to determine the optimal conditions for seed germination of eight Pedicularis species, based on their responses to light and several artificial treatments. Knowledge of the effects of these treatments on seed germination of these eight species will ensure that enough plants can be produced for further study of cultivation and thus contribute to the success of their domestication.

\section{Materials and Methods}

Study species, seed collection, and storage. To guarantee sufficient seeds for germination tests, eight Pedicularis species with large populations from the northwestern Yunnan Province in China were chosen as test species (Table 1). We noticed that the plants of $P$. longiflora Rudolph growing in Baimaxueshan were much shorter than those growing in Zhongdian, often two to three times shorter in height. Accordingly, seeds of this species collected from both sites were studied to examine whether there would be differences in germination characteristics between the seeds from the two localities. Among these eight species, $P$. rex C.B. Clarke and $P$. longiflora are valuable materials for Chinese traditional herbs (Wu et al., 2002). The rest of the species are promising ornamental plants. According to Tsoong (1963), all eight species are perennial herbs except for P. longiflora and P. pseudomelampyriflora Bonati, which are annual herbaceous species. These species are commonly distributed in alpine/subalpine meadows. Most of them prefer humid habitats, although some species ( $P$. dichotoma Bonati) are often found in dry calcareous grasslands and some (P. longiflora, P. cephalantha Franch., and $P$. siphonantha Don) are frequently found in swampy places. Seeds of these tested species often mature from August to September in northwestern Yunnan Province. In our experiments, seeds of eight Pedicularis species (including nine accessions) were collected from Aug. to Nov. 2004. Species identification was based on morphological characteristics described in Flora Reipublicae Popularis Sinicae (Tsoong, 1963). Seeds were allowed to dry at room temperature for about half a month and were stored in paper bags at $4{ }^{\circ} \mathrm{C}$ in a refrigerator until used. Germination experiments were conducted in Dec. 2004

Experimental setup. All germination tests were carried out on three layers of filter paper saturated with distilled water in transparent glass Petri dishes. To guarantee constant moisture in the dishes, they were connected to an extra dish filled with distilled water by a filter paper band. Two light regimes (16 h light $/ 8 \mathrm{~h}$ dark and complete darkness) and three artificial treatments were used in our experiments. For the treatment in darkness, the dishes were put into a paper box wrapped with aluminum foil. For artificial treatments, seeds were either scarified by rubbing against 120 -grit sandpaper until the seed coat was penetrated or was soaked in gibberellic acid 
Table 1. Information about sampling sites and mass of 1000 seeds of the nine accessions of Pedicularis.

\begin{tabular}{llcc}
\hline Species & \multicolumn{1}{c}{ Location } & $\begin{array}{c}\text { Elevation } \\
(\mathrm{m})\end{array}$ & $\begin{array}{c}\text { Mass of } \\
1000 \text { seeds }(\mathrm{g})\end{array}$ \\
\hline Pedicularis rex C.B. Clarke & Lat. $25^{\circ} 39^{\prime} \mathrm{N}$, long. $100^{\circ} 07^{\prime} \mathrm{E}$ & 2710 & 3.2 \\
$P$. longiflora Rudolph (Zhongdian) & Lat. $27^{\circ} 36^{\prime} \mathrm{N}$, long. $99^{\circ} 43^{\prime} \mathrm{E}$ & 3140 & 0.8 \\
$P$. longiflora Rudolph (Baima) & Lat. $28^{\circ} 18^{\prime} \mathrm{N}$, long. $99^{\circ} 07^{\prime} \mathrm{E}$ & 3770 & 0.6 \\
$P$. dichotoma Bonati & Lat. $27^{\circ} 13^{\prime} \mathrm{N}$, long. $99^{\circ} 38^{\prime} \mathrm{E}$ & 3210 & 1.0 \\
$P$. lutescens Franch. & Lat. $27^{\circ} 48^{\prime} \mathrm{N}$, long. $99^{\circ} 43^{\prime} \mathrm{E}$ & 3330 & 0.6 \\
$P$. cephalantha Franch. & Lat. $27^{\circ} 01^{\prime} \mathrm{N}$, long. $100^{\circ} 13^{\prime} \mathrm{E}$ & 2740 & 1.8 \\
$P$. siphonantha Don & Lat. $27^{\circ} 38^{\prime} \mathrm{N}$, long. $99^{\circ} 38^{\prime} \mathrm{E}$ & 3840 & 0.3 \\
$P$. tenuisecta Franch. & Lat. $27^{\circ} 38^{\prime} \mathrm{N}$, long. $99^{\circ} 38^{\prime} \mathrm{E}$ & 3840 & 0.7 \\
$P$. pseudomelampyriflora & Lat. $27^{\circ} 02^{\prime} \mathrm{N}$, long. $100^{\circ} 13^{\prime} \mathrm{E}$ & 2740 & 1.1 \\
\hline
\end{tabular}

$\left(\mathrm{GA}_{3} ; 100\right.$ and $500 \mathrm{mg} \cdot \mathrm{L}^{-1}$, respectively) for $2 \mathrm{~h}$. All tests were carried out in a growth chamber (Yi-Heng Technology Co., Ltd., model MGC-300A, series Blue Pard; Shanghai, China) with a cycle of $16 \mathrm{~h}$ light (44.4 $\left.\mu \mathrm{mol} \cdot \mathrm{m}^{-2} \cdot \mathrm{s}^{-1}, 400-700 \mathrm{~nm}\right)$ at $25^{\circ} \mathrm{C}$ and $8 \mathrm{~h}$ dark at $18{ }^{\circ} \mathrm{C}$. This temperature and light regime was chosen based on the temperature and light found to produce optimal germination in other studies of high-elevation species (Giménez-Benavides et al., 2005; Li et al., 1997). Each treatment consisted of three replications of 20 seeds.

Germination counts. Seeds were considered germinated when the radicle reached to half the length of the seed. Germination was monitored at 2-d intervals for analysis of the germination dynamics of individual species. Dark-treated germination counts were conducted under a green safelight in a dark room. Germination percentage was used as a parameter for analysis in this study and was calculated by the following equation:

Germination percentage $=$

(number of germinated seeds/

total number of seeds tested) $\times 100$

In one of the three replicates of $P$. tenuisecta Franch., 100\% of the seeds germinated after $10 \mathrm{~d}$ of incubation. Thus, germination percentage on the 10th day was used to analyze the effects of different treatments on seed germination and variation among various species. However, germination counts were continued until the 12th day for a better analysis of germination dynamics of the tested species.

A cut test was conducted at the end of the tests to assess the health of ungerminated seeds. Seeds with a plump, firm, and white embryo were considered viable (Kenny, 2000).

Statistical analysis. All germination percentage data were arcsine transformed before statistical analysis. One-way analysis of variance was performed using SPSS version 14.0 (SPSS China Ltd., Shanghai, China) and Duncan's multiple range test was used to evaluate differences among the means. Significance was reported at $P<0.05$.

\section{Results}

Four (P. rex, $P$. lutescens Franch., $P$. tenuisecta, and $P$. pseudomelampyriflora) of eight species were insensitive to light, with no significant difference in germination at
$25{ }^{\circ} \mathrm{C} / 18{ }^{\circ} \mathrm{C}$ when seeds were incubated in light or complete darkness (Fig. 1). But in both seed sets of $P$. longiflora and in $P$. siphonantha, all seeds failed to germinate in complete darkness. Seed germination percentage of $P$. cephalantha was also significantly decreased when incubated in complete darkness. By contrast, in P. dichotoma germination was significantly enhanced by darkness.

Based on statistical analysis, scarifying seed coat with sandpaper resulted in significantly improved germination in all tested Pedicularis species except $P$. lutescens (Fig. 1). Scarification was the most effective germination promoting method, showing a significantly positive effect in six of eight species when compared with other treatments.

With regard to the effects of $\mathrm{GA}_{3}$ on seed germination of tested species, some inconsistencies were detected (Fig. 1). In five cases, $\mathrm{GA}_{3}$ either had no effect on germination or led to a decrease ( $P$. cephalantha and $P$. tenuisecta). In four species $[P$. rex, $P$. longiflora (Baima), $P$. dichotoma, and P. pseudomelampyriflora], $\mathrm{GA}_{3}$ led to a small significant increase in germination. However, in three of four cases this only occurred for one of the concentrations examined.

Two seed sets of $P$. longiflora from different sites showed similar germination characteristics in that both were significantly promoted by scarification and completely inhibited by darkness (Fig. 1). However, the overall germination percentage in $P$. longiflora (Baima) was slightly higher than that in P. longiflora (Zhongdian). Also, germination of $P$. longiflora (Baima) was improved after treatment with $\mathrm{GA}_{3}$ at $500 \mathrm{mg} \cdot \mathrm{L}^{-1}$, whereas neither at $100 \mathrm{mg} \cdot \mathrm{L}^{-1}$ nor at $500 \mathrm{mg} \cdot \mathrm{L}^{-1}$ was $\mathrm{GA}_{3}$ found to promote germination of P. longiflora (Zhongdian).

Difficulty of promoting germination with artificial treatments varied between species (Fig. 2). For example, seeds of P. pseudomelampyriflora scarified with sandpaper gave the fastest and most uniform germination, with $100 \%$ germination after $10 \mathrm{~d}$, but some species ( $P$. longiflora and $P$. siphonantha) germinated at very low percentages. For most tested species, it took a rather long period of time to reach a high germination percentage. Some species germinated faster than others, but still at least $6 \mathrm{~d}$ were needed to reach $50 \%$ germination (Fig. 2).

The cut test conducted on ungerminated seeds by the end of the germination tests showed that the majority had a well-developed, intact, and healthy embryo, with the exception of a few decayed ones because of fungi contamination.

\section{Discussion}

Individual species of Pedicularis varied considerably not only in their responses to different treatments (Fig. 1), but also in their rate of germination under the same treatments (Fig. 2). This agrees with Song et al. (2005), who suggested that optimal conditions for seed germination may differ in various species of the same genus. Variation of germination behavior among species may be attributed to ecological adaptation to their respective habitats (Bruna, 1999; Meyer and Kitchen, 1994; Meyer et al., 1990). Various adaptation mechanisms may

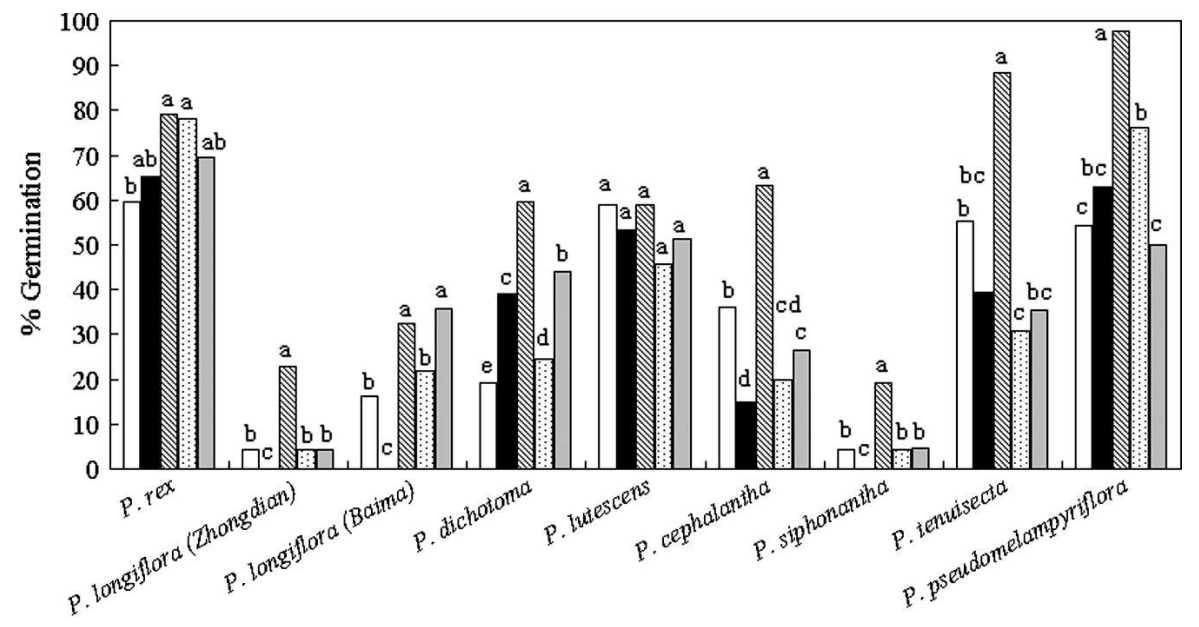

Pedicularis species

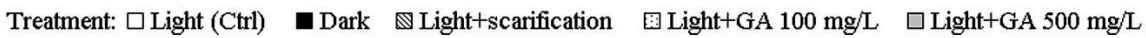

Fig. 1. Effect of light, scarification, and gibberellic acid on germination of eight tested species of Pedicularis (including two seed sets of $P$. longiflora). Letters for the same species indicate a significant difference among the treatments by one-way analysis of variance and Duncan's multiple range test at $P<0.05$. Absence of bars means values were zero. GA, gibberellic acid. 

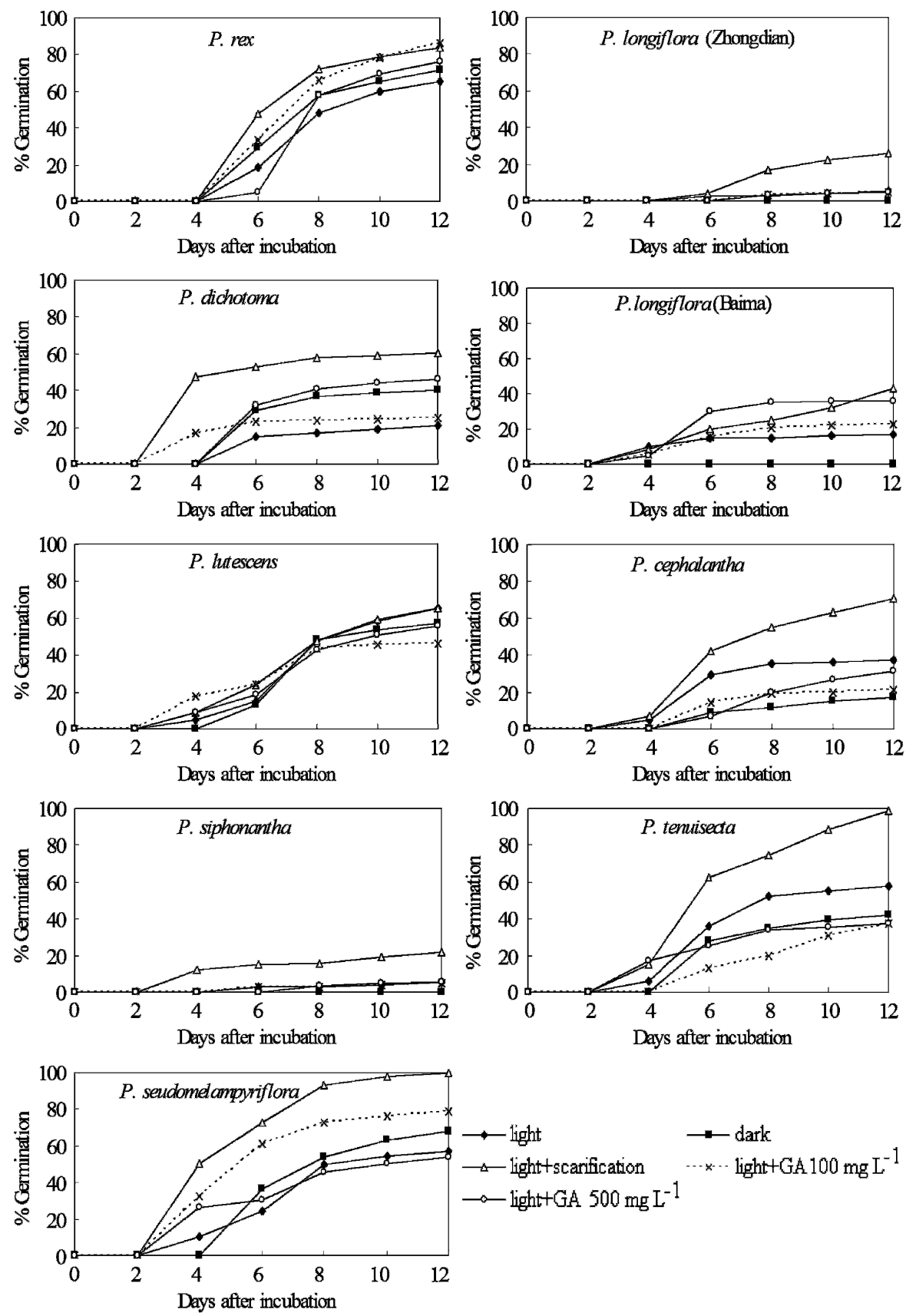

Fig. 2. Germination curves for eight tested Pedicularis species (including two seed sets of P. longiflora) given various treatments. GA, gibberellic acid.

have been developed in different habitats during the long history of evolution, and therefore sensitivity to environmental factors (such as light) varies (Baskin and Baskin, 1971; Meyer and Monsen, 1991). In our experiments, all the species with germination inhibited significantly by darkness were collected from swampy habitats. According to Grime et al. (1981), many wet-habitat species require light for germination compared with "dryish" habitat species. The requirement for light may be an adaptation to a waterlogged habitat, in which seed germination is triggered in nature only by sufficient light exposure so that seeds will not germinate in dim light conditions (such as deep water), thus preventing seedlings from being submersed by deep water that may cause great mortality. On the contrary, seed germination of $P$. dichotoma was promoted by darkness, which may be explained by its dryish calcareous habitats in which seedling survival over the dry season is enhanced when the seeds germinate below the soil surface. We are not alone on this point. In their experiments with some Western Australian species, Bell et al. (1999) found that perennial species from habitats with sand or gravel-dominated soils showed negatively photoblastic responses.

In terms of artificial germination promoting treatments, although previous studies on other Pedicularis species suggested a pro- moting effect from $\mathrm{GA}_{3}$ (Evans et al., 2001), scarification with sandpaper was more effective than treatment with $\mathrm{GA}_{3}$ in our experiments. This may be the result of the removal (or partially removal) of the seed coat and other seed structures that otherwise inhibit the absorption of light or water (Pezzani and Montaña, 2006). However, our results do not exclude the possibility that application of higher concentrations of $\mathrm{GA}_{3}$ may have a significant germination-promoting effect on some species, and it is possible that $\mathrm{GA}_{3}$ would have promoted germination if it had been combined with a scarification treatment. According to Cochrane et al. (2002), the conjunction of scarification with $\mathrm{GA}_{3}$ showed a better germination-promoting effect on some taxa of Myoporaceae, Lamiaceae, and Myrtaceae than either single treatment.

Two seed sets of $P$. longiflora showed similar germination characteristics on the whole. This may be the result of similar genetic systems as well as similar habitats. Although response to $\mathrm{GA}_{3}$ treatment differed a little bit between the two seed sets, the significance of this finding is unclear because the overall germination levels were rather low in these cases. A slightly higher overall germination percentage in $P$. longiflora (Baima) than $P$. longiflora (Zhongdian) may be explained by seed quality difference between the two collecting sites.

Most Pedicularis species cannot germinate immediately after harvest, which has been ascribed to physiological dormancy, and months of cold stratification was suggested to break it (Evans et al., 2001; Li et al., 1997). Although we do not exclude the possibility that the seeds we used may have come out of dormancy (or partially out of dormancy) after storage at $4{ }^{\circ} \mathrm{C}$ for about 3 months, our findings suggest that not all species require up to several months of wetcold stratification for germination. Also, the hemiparasitic species studied in our study seemed to be independent of host plants for germination, thus differing from holoparasitic members of Orobanchaceae that germinate only in response to specific signals from host plants (Batchvarova et al., 1999; Zhou et al., 2004).

The fact that ungerminated seeds were still viable after a period of incubation suggests a soil seed bank for some Pedicularis species that have developed such a mechanism to ensure that only a proportion of seeds germinated at one time. Thus, the remainder survive in a dormant condition, waiting for the right time and the most favorable conditions. In view of uncertain conditions for seedling development because of dramatic soil moisture and temperature fluctuation in high-elevation areas, natural selection in these areas may favor seeds with a genetic system for dormancy and delayed germination (Kaye, 1997). Accordingly, seed dormancy and a soil seed bank strategy may be common for high-elevation plants like Pedicularis.

To conclude, scarification might be used as an effective method to promote seed 
germination in cultivation of Pedicularis species. Because seed germination of some species was inhibited by darkness, care must be taken not to sow these species too deeply to avoid dark inhibition. Surface sowing, then slightly covering seeds with fine soil, may be a safe sowing practice unless a species is found to have negative photoblastic responses. In the process of introduction and cultivation of plants belonging to this genus, it will be important to allow sufficient time for germination to take place unless scarification treatments or other effective methods can be applied to speed up the process.

\section{Literature Cited}

Allard, D.J. 2001. Pedicularis lanceolata Michx. Swamp Wood-betony. New England Plant Conservation Program-conservation and research plan. New England Wild Flower Soc., Framingham, MA.

Angiosperm Phylogeny Group. 2003. An update of the Angiosperm Phylogeny Group classification for the orders and families of flowering plants: APG II. Bot. J. Linn. Soc. 141:399-436.

Baskin, J.M. and C.C. Baskin. 1971. Germination ecology and adaptation to habitat in Leavenworthia spp. (Cruciferae). Amer. Midl. Nat. 85:22-35.

Batchvarova, R.B., S.B. Slavov, and S.N. Bossolova. 1999. In vitro culture of Orobanche ramosa. Weed Res. 39:191-197.

Bell, D.T., L.A. King, and J.A. Plummer. 1999. Ecophysiological effects of light quality and nitrate on seed germination in species from Western Australia. Aust. J. Ecol. 24:2-10.

Bruna, E.M. 1999. Seed germination in rainforest fragments. Nature 402:139.

Canadian Endangered Species Conservation Council (CESCC). 2002. Annual report for 20012002 on the recovery of national endangered wildlife. CESCC, Halifax, N.S.

Cochrane, A., A. Kelly, K. Brown, and S. Cunneen. 2002. Relationships between seed germination requirements and ecophysiological characteristics aid the recovery of threatened native plant species in Western Australia. Ecol. Mgt. Ecol. Mgt. Rest. 3:47-60.

Evans, J., T. Luna, and D. Wick. 2001. Propagation protocol for production of container Pedicularis groenlandica Retz. plants (172 $\mathrm{ml}$ conetainers);
Glacier National Park, West Glacier, MT. In: Native Plant Network. 12 June 2006. <www. nativeplantnetwork.org $>$.

Giménez-Benavides, L., A. Escudero, and F. Pérez-García. 2005. Seed germination of high mountain Mediterranean species: Altitudinal, interpopulation and interannual variability. Ecol. Res. 20:433-444.

Grime, J.P., G. Mason, A.V. Curtis, J. Rodman, S.R. Band, M.A.G. Mowforth, A.M. Neal, and S. Shaw. 1981. A comparative study of germination characteristics in a local flora. J. Ecol. 69:1017-1059.

Jensen, K. 2004. Dormancy patterns, germination ecology, and seed-bank types of twenty temperate fen grassland species. Wetlands 24:152166.

Kaye, T.N. 1997. Seed dormancy in high elevation plants: Implications for ecology and restoration, p. 115-120. In: T.N. Kaye, A. Liston, R.M. Love, D.L. Luoma, R.J. Meinke, and M.V. Wilson (eds.). Conservation and management of native plants and fungi. Native Plant Society of Oregon, Corvallis, OR.

Kenny, B.J. 2000. Influence of multiple fire-related germination cues on three Sydney Grevillea (Proteaceae) species. Austral. Ecol. 25:664 669.

Li, J.X., K.Y. Guan, Y.C. Li, J. Kuang, and F.C. Kong. 1997. Studies on introduction and cultivation of Pedicularis tricolor. Guihaia 17:255258. in Chinese.

Macior, L.W. 1975. The pollination ecology of Pedicularis (Scrophulariaceae) in the Yukon Territory. Amer. J. Bot. 62:1065-1072.

Macior, L.W. 1983. The pollination dynamics of sympatric species of Pedicularis (Scrophulariaceae). Amer. J. Bot. 70:844-853.

Macior, L.W. and Y. Tang. 1997. A preliminary study of the pollination ecology of Pedicularis in the Chinese Himalaya. Plant Species Biol. 12:1-7.

Marvier, M.A. and D.L. Smith. 1997. Conservation implications of host use for rare parasitic plants. Cons. Biol. 11:839-848.

McDonough, W.T. 1970. Germination of 21 species collected from a high-elevation rangeland in Utah. Amer. Midl. Nat. 84:551-554.

Meyer, S.E. and S.G. Kitchen. 1994. Habitatcorrelated variation in seed germination response to chilling in Penstemon Section Glabri (Scrophulariaceae). Amer. Midl. Nat. 132:349-365.
Meyer, S.E. and S.B. Monsen. 1991. Habitatcorrelated variation in mountain big sagebrush (Artemisa tridentata ssp. vaseyana) seed germination patterns. Ecology 72:739-742.

Meyer, S.E., S.B. Monsen, and E.D. McArthur. 1990. Germination response of Artemisa tridentata (Asteraceae) to light and chilly patterns of between-population variation. Bot. Gaz. 151:176-183.

Pezzani, F. and C. Montaña. 2006. Inter- and intraspecific variation in the germination response to light quality and scarification in grasses growing in two-phase mosaics of the Chihuahuan Desert. Ann. Bot. (Lond.) 97:1063-1071.

Ree, R.H. 2005. Phylogeny and the evolution of floral diversity in Pedicularis (Orobanchaceae). Int. J. Plant Sci. 166:595-613.

Song, W.J., W.J. Zhou, Z.L. Jin, D.D. Cao, D.M Joel, Y. Takeuchi, and K. Yoneyama. 2005. Germination response of Orobanche seeds subjected to conditioning temperature, water potential and growth regulator treatments. Weed Res. 45:467-476.

Tsoong, P.C. 1963. Scrophulariaceae, p. 1-378. In: S.S. Chien and W.Y. Chun (eds.). Flora reipublicae popularis sinicae. Vol. 68. Science Press, Beijing. in Chinese.

Wang, C.Z. and Z.J. Jia. 1995. The chemical constituents of Pedicularis chinensis. Chem. J. Chin. Univ. 16:1747-1748. in Chinese.

Wang, H., W.L. Li, and J. Cai. 2003. Correlations between floral diversity and pollination patterns in Pedicularis (Scrophulariaceae). Acta Bot. Yunnanica 25:63-70. in Chinese.

Wu, Z., F.R. Li, and J.X. Yang. 2002. Advances in studies of medicinal plants of Pedicularis L. Shenzhen J. Tradit. Chin. Medic. Res. 13:305307. in Chinese.

Yang, H.P., N.H. Holmgren, and R.R. Mill. 1998. Pedicularis L., p. 97-209. In: Z.Y. Wu and P.H. Raven (eds.). Flora of China. Vol. 18. Science Press, Beijing and Missouri Botanical Garden Press, St. Louis, MO.

Zhou, W.J., K. Yoneyama, Y. Takeuchi, S. Iso, S. Rungmekarat, S.H. Chae, D. Sato, and D.M. Joel. 2004. In vitro infection of host roots by differentiated calli of the parasitic plant Orobanche. J. Expt. Bot. 55:899-907.

Zhu, Z.Y. 1997. Study on clinical application and medicinal properties of Pedicularis L. Shenzhen J. Tradit. Chin. Medic. Res. 8:103-104. in Chinese. 